\title{
Densidade de plantio e substâncias húmicas no cultivo do tomateiro (Solanum lycopersicum L.)
}

\author{
Rafael Benetti ${ }^{1}$, Katiane Santiago Silva Benett ${ }^{1}$, Natália Arruda ${ }^{1}$, Cleiton Gredson Sabin \\ Benett $^{1}$, Alexsander Seleguini ${ }^{2}$ \\ ${ }^{1}$ Universidade Estadual de Goiás, Campus de Ipameri. Ipameri, Goiás, Brasil. E-mail: rafbtti@ yahoo.com.br, \\ katiane.benett@gmail.com, nathy.a@hotmail.com, cleiton.benett@gmail.com \\ ${ }^{2}$ Universidade Federal do Triângulo Mineiro, Campus Iturama, Iturama, Minas Gerais, Brasil. E-mail: aseleguini@gmail.com
}

Recebido: 04/10/2017; Aceito: 24/01/2018

\section{RESUMO}

O tomate é uma das hortaliças tipo fruto mais populares do Brasil. Desta forma, torna-se de suma importância realizar pesquisas para garantir produtividade e frutos de alta qualidade. Objetivo do trabalho foi avaliar diferentes doses de ácidos húmicos e fúlvicos sobre o crescimento e produtividade do tomateiro cultivado com diferentes densidades de plantio. O experimento foi realizado na fazenda da Universidade Estadual de Goiás (UEG), Campus de Ipameri. Foi adotado os espaçamentos de 0,30 e $0,50 \mathrm{~m}$ entre plantas, correspondendo, respectivamente, às populações de 33.333 e 20.000 plantas ha $^{-1}$; com as diferentes doses $\left(0,20,40,60\right.$ e $\left.80 \mathrm{~L} \mathrm{ha}^{-1}\right)$ de ácidos húmicos e fúlvicos. O delineamento experimental utilizado foi de blocos casualizados em esquema fatorial $2 \times 5$ (espaçamentos $\mathrm{x}$ doses de ácidos) com quatro repetições. Os dados foram submetidos à análise de variância e as médias comparadas pelo teste de Tukey a 5\% de probabilidade. A produtividade do tomateiro foi maior no espaçamento de $0,50 \mathrm{~cm}$, e as doses crescentes de ácidos húmicos e fúlvicos influenciaram positivamente no teor de clorofila e na firmeza do tomate de mesa. Conclui-se que para o adequado cultivo do Híbrido Santy, recomenda-se a densidade de plantio de 20.000 plantas $^{-1} a^{-1}$ e doses crescentes de substâncias húmicas que assim garantem alta produtividade e qualidade dos frutos.

Palavras-chave: Ácidos húmico, ácido fúlvicos, arranjo de plantas, rendimento, crescimento

\section{Planting density and humic substances in growing tomato (Solanum lycopersicum $\mathbf{L}$. )}

\begin{abstract}
Tomato is one of the most popular vegetables, so it is very important to carry out research to ensure high quality fruit and yield. The objective of this work was to evaluate different doses of humic and fulvic acids on the growth and yield of tomato cultivated with different planting densities. The experiment was carried out on the farm of the State University of Goiás (UEG), Ipameri Campus. The spacings of 0.30 and $0.50 \mathrm{~m}$ between plants were adopted, corresponding, respectively, to the populations of 33,333 and 20,000 plants $^{-1} a^{-1}$; with different rates $(0$, 20, 40, 60 and $\left.80 \mathrm{~L} \mathrm{ha}^{-1}\right)$ of humic and fulvic acids. The experimental design was randomized blocks in a factorial scheme $2 \times 5$ (spacings $\mathrm{x}$ acid rates) with four replications. The data were submitted to analysis of variance and the means were compared by the Tukey test at $5 \%$ probability. The productivity of the tomato was higher in the spacing of $0.50 \mathrm{~cm}$, and the increasing doses of humic and fulvic acids had a positive influence on the chlorophyll content and firmness of the table tomato. It is concluded that for the adequate cultivation of the Santy Hybrid, it is recommended the planting density of 20,000 $\mathrm{ha}^{-1}$ plants and increasing doses of humic substances, thus guaranteeing high productivity and fruit quality.
\end{abstract}

Key words: Humic acids, fulvic acids, arrangement plants, yield, growth. 


\section{Introdução}

O consumo do tomate (Solanum lycopersicum L.) faz parte dos hábitos alimentares dos brasileiros e sua produção exige uma grande gama de conhecimentos e tecnologias, para se caracterize como uma atividade sustentável. Portanto, o estudo de novos produtos e técnicas de cultivo se faz necessário para oferecer alternativas eficientes à cadeia produtiva do tomateiro. Além das exigências do campo, o produtor precisa atender as exigências do mercado consumidor, com frutos de alta qualidade, principalmente para o consumo in natura; um dos setores mais competitivos.

Dentre os fatores que influenciam na qualidade dos frutos, a nutrição é considerada um dos mais importantes. Os produtos à base de ácidos húmicos e fúlvicos, que são compostos orgânicos condicionadores do solo ajudam a melhorar o aproveitamento da adubação mineral. Outro fator importante no aproveitamento dos macros e micronutrientes presentes no solo é a adequada densidade de plantas, com o intuito de evitar excesso de competição entre as plantas ou a subutilização do solo (MEURER, 2012).

A maior parte do carbono orgânico da superfície do planeta encontra-se na matéria orgânica humificada, ou seja, nas substâncias húmicas. Os compostos de carbono gerados na decomposição dos resíduos orgânicos sofrem processos de ressíntese chamados de humificação, formando um material genericamente conhecido como "húmus". Esta substância pode ser encontrada no solo, intimamente associado a outros constituintes e mesmo dentro de agregados (BALDOTTO; BALDOTTO, 2014).

Os ácidos húmicos são responsáveis por uma série de processos químicos e bioquímicos, como a capacidade de retenção de nutrientes, a complexação e transporte de cátions e reações fisiológicas em microorganismos e plantas (ZANDONADI et al., 2014). Os teores de ácidos húmicos e fúlvicos ideais para os cultivos é um tema que atualmente está sendo estudado. Contudo, alguns trabalhos indicam que as culturas respondem à ação dessas substâncias até determinado nível, e que concentrações elevadas resultam em diminuição do crescimento e do desenvolvimento das plantas (BALDOTTO; BALDOTTO, 2013; BALDOTTO et al., 2014).

Os ácidos húmicos e fúlvicos podem ser utilizados em diversas culturas, como demonstra Wangen et al. (2013), que utilizaram na cultura da couve-da-malásia (Brassica chinensis L.) o produto comercial Codahumus $20^{\circledR}$, o qual apresentou resultados promissores, proporcionando incremento na produção de massa fresca e massa seca da parte aérea das plantas. Bernardes et al. (2011), utilizando o mesmo produto na produção de mudas de tomateiro, constataram que a dose de $0,96 \mathrm{~mL} \mathrm{dm}^{-3}$ associado ao substrato comercial
Plantmax ${ }^{\circledR}$ Hortaliças HT proporcionou a mudas de melhor qualidade.

Em relação ao sistema de produção para a cultura do tomate tutorada, os espaçamentos mais utilizados são 100 a $120 \mathrm{~cm}$ entre fileiras por 40 a $70 \mathrm{~cm}$ dentro da linha de plantio (FILGUEIRA, 2012). Machado et al. (2007), ressaltam a possibilidade de aumentar o peso médio dos frutos do tomateiro com o emprego do espaçamento entre plantas de $50 \mathrm{~cm}$ para o híbrido Heinz 9780 , e 35 ou $50 \mathrm{~cm}$ para o híbrido Kátia, e da poda apical após dois ou quatro cachos. Segundo Mueller e Wamser (2009), as maiores produtividades são obtidas com o menor espaçamento e a maior altura de desponta.

$\mathrm{Na}$ literatura há poucas informações quanto à utilização de ácidos húmicos e fúlvicos relacionada à densidade de plantio para o cultivo do tomateiro de forma tutorada nas condições climáticas do Cerrado. Diante do exposto, o objetivo dessa pesquisa foi determinar a melhor dose dos ácidos húmicos e fúlvicos em função da densidade de plantio, para a produção de tomates de mesa

\section{Material e Métodos}

As atividades de pesquisa foram executadas em área pertencente à Universidade Estadual de Goiás (UEG), Campus de Ipameri-GO, situada às margens da rodovia

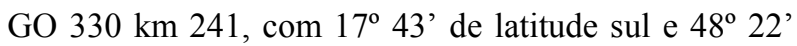
de longitude oeste e altitude de $800 \mathrm{~m}$. O clima do município, segundo a classificação de Köppen (1928), é definido como Tropical Úmido (AW), constando temperaturas elevadas, com chuvas no verão e seca no inverno.

O solo da área experimental é classificado como Latossolo Vermelho-Amarelo Distrófico (EMBRAPA, 2013). As características químicas da camada superficial de 0 a $20 \mathrm{~cm}$ do solo da área do experimento apresentou a seguinte composição química: $\mathrm{pH}$ $\left(\mathrm{CaCl}_{2}\right)=5,4 ; \mathrm{H}+\mathrm{Al}=29 \mathrm{mmol}_{\mathrm{c}} \mathrm{dm}^{-3} ; \mathrm{Ca}=19 \mathrm{mmol}_{\mathrm{c}}$ $\mathrm{dm}^{-3} ; \mathrm{Mg}=13 \mathrm{mmol}_{\mathrm{c}} \mathrm{dm}^{-3} ; \mathrm{P}$ (resina) $=14 \mathrm{mg} \mathrm{dm}^{-3} ; \mathrm{K}=$ $3,2 \mathrm{mmol}_{\mathrm{c}} \mathrm{dm}^{-3}$; Matéria orgânica $=26 \mathrm{~g} \mathrm{dm}^{-3}$; CTC $=$ $64,2 \mathrm{mmol}_{\mathrm{c}} \mathrm{dm}^{-3} ; \mathrm{V} \%=55 ; \mathrm{Cu}=1,0 \mathrm{mg} \mathrm{dm}^{-3} ; \mathrm{Fe}=57$ $\mathrm{mg} \mathrm{dm}^{-3} ; \mathrm{Mn}=2,9 \mathrm{mg} \mathrm{dm}^{-3} ; \mathrm{Zn}=0,3 \mathrm{mg} \mathrm{dm}^{-3}$ e $\mathrm{B}=0,15$ $\mathrm{mg} \mathrm{dm}{ }^{-3}$.

Utilizou-se o híbrido de tomate de mesa Santy do segmento salada indeterminado; o controle dos insetos pragas e de doenças foi realizado de forma preventiva, utilizando-se diversos inseticidas e fungicidas recomendados para a cultura. As mudas do tomate foram produzidas em estufa agrícola, em bandejas de poliestireno expandido, com 128 células preenchidas com substrato organomineral comercial. O transplante das mudas foi realizado 30 dias após a semeadura e as mudas foram transplantadas para o campo após o 
preparo do solo. A adubação de plantio foi feita no sulco com o formulado 04-14-08 de acordo com a análise química do solo; as plantas foram conduzidas com duas hastes e tutoradas com estacas de bambu utilizando-se o gotejamento o sistema de irrigação.

O fertilizante orgânico utilizado foi composto por ácidos húmicos e fúlvicos com a seguinte composição: $\mathrm{g}$ $\mathrm{L}^{-1}=224,0$ de extrato húmico total, 111,0 de ácidos húmicos, 113,0 de ácidos fúlvicos, 129,0 de carbono orgânico total e 7,2 de nitrogênio solúvel em água. Utilizou-se as doses de 0, 20, 40, 60 e $80 \mathrm{~L} \mathrm{ha}^{-1}$ de ácido húmico e fúlvico; as aplicações dos tratamentos com os ácidos iniciar na primeira semana após o transplante das mudas e seguiram com intervalos de 15 dias até totalizar as quatro aplicações. Além das diferentes doses de ácidos foi adotado espaçamento de 0,30 e 0,50 m entre plantas e 1,0 m entre linhas, correspondendo, respectivamente, às populações de 33.333 e 20.000 plantas $\mathrm{ha}^{-1}$.

Para determinar o crescimento e produtividade do tomateiro realizaram-se as seguintes avaliações: a) altura média do primeiro cacho: determinada a partir da superfície do solo até a inserção da penca com o ramo principal; b) altura média de plantas: medindo-se a altura do colo da planta até a gema apical do ramo principal da planta; c) diâmetro médio do caule: utilizou-se um paquímetro digital, realizando-se a medida na altura de $2 \mathrm{~cm}$ da superfície do solo, no colo da planta; d) taxa de crescimento absoluto: obtidas as taxas médias de crescimento absoluto para o comprimento de planta, em intervalos de 15 dias, a partir da seguinte formula: $\mathrm{TCA}=\left(\mathrm{CP}_{2}-\mathrm{CP}_{1}\right) /\left(\mathrm{T}_{2}-\right.$ $\mathrm{T}_{1}$ ), formula adaptada de Hunt (1990), e o resultado foi expresso em $\mathrm{cm} \mathrm{dia}^{-1}$; d) clorofila: foi determinado o teor de clorofila pelo método não destrutivo, utilizando o aparelho clorofiLOG ${ }^{\circledR}$ (FALKER), por meio da leitura com clorofilômetro, o qual determina indiretamente a concentração de clorofila nas folhas; e) produção comercial média por unidade de área: produtividade média dos frutos colhidos no ponto de maturação fisiológica, em cada parcela.

Para análises físico-químicas dos frutos do tomateiro foram realizadas as seguintes avaliações: a) $\mathrm{pH}$ (potencial hidrogeniônico); b) acidez total titulável (ATT): determinada por titulação com solução de $\mathrm{NaOH}(0,05 \mathrm{~N})$, e $30 \mathrm{~mL}$ de suco puro de tomate; c) teor de sólidos solúveis totais (SST): foi determinado do refratômetro manual Abbe Carl Zeiss ${ }^{\circledR}$, a leitura foi expressa em grau ${ }^{\circ}$ Brix; d) Índice de maturação (SST/ATT): determinado a partir da relação do teor de sólidos solúveis totais (SST) com acidez total titulável (ATT); e) grau de firmeza do fruto: utilizou-se um Penetrômetro Wagne ${ }^{\circledR}$, medindo a compressão até a ruptura da casca dos frutos; f) classificação dos frutos por tamanho: os frutos foram classificados de acordo com seu diâmetro em: grande (80-100 mm), médio (65$80 \mathrm{~mm}$ ) e pequeno $(50-65 \mathrm{~mm})$, medida do diâmetro transversal do fruto (PBMH, 2003).

O delineamento experimental utilizado foi blocos casualizados, arranjados em esquema fatorial $5 \times 2$, sendo cinco doses de ácidos húmicos e fúlvicos e duas densidades de plantio, com quatro repetições e cinco plantas por parcela. Os dados foram submetidos à análise de variância e as médias foram comparadas pelo teste de Tukey $(\mathrm{p}<0,05)$, ao passo que os efeitos das doses do ácido húmico e fúlvico testadas foram descritas quando significativas e realizadas equações de regressão polinomial. Para análise de estatística foi utilizado o programa Sanest.

\section{Resultados e Discussão}

O híbrido de tomate Santy não apresentou diferenças significativas para a altura do primeiro cacho, altura de plantas e taxa de crescimento absoluto da altura de plantas, nos dois espaçamentos de plantio avaliados, conforme apresentado na Tabela 1. Contudo, apesar de não haver diferenças entre os espaçamentos, observouse, nas plantas cultivadas em espaçamento maior, altura do primeiro cacho de frutos e a altura de plantas, maiores do que aquelas cultivadas no espaçamento menor.

Estudo realizado por Silva e Faria Junior (2011), com diferentes concentrações de paclobutrazol em híbridos de tomateiro AF 7631 e Jennifer, apresentaram resultados inferiores ao desta pesquisa (Tabela 1); 106,72 e 114,26 cm para altura de planta e 1,63 e 1,76 $\mathrm{cm}$ dia $^{-1}$ para taxa média de crescimento absoluto respectivamente. Nas avaliações de altura do primeiro cacho, altura da planta, diâmetro de caule e taxa de crescimento absoluto para altura de plantas, não foram detectadas interações significativas entre os espaçamentos estudados e as doses de ácido húmico e fúlvico (Tabela 1). Em trabalhos com mudas de tomate, Bernardes et al. (2011), encontraram resultados significativos para o uso do produto Codahumus $20^{\circledR}$ na produção de mudas de tomate. As mudas sem a aplicação da substância apresentaram a altura média de $4,69 \mathrm{~cm}$, valor este inferior ao das mudas tratadas, indicando que a presença do ácido húmico e/ou ácido fúlvico pode ter influenciado no acréscimo desta variável.

Quanto ao diâmetro de caule, constatou-se diâmetro superior para as plantas conduzidas no espaçamento de 30 $\mathrm{cm}$ entre plantas em comparação às plantas conduzidas em espaçamento de $50 \mathrm{~cm}$ (Tabela 1). De acordo com Seleguini et al. (2016), plantas com diâmetro maior podem ser mais resistentes à quebra das hastes, quer seja pela pressão exercida por altas cargas de frutos ou decorrentes de ventos ou a combinação dos dois fatores. 
Tabela 1. Valores médios para altura do primeiro cacho (APC), altura da planta (AP), diâmetro de caule (DC), taxa de crescimento absoluto para altura de plantas (TCAAP) e índice de clorofila (CLOR) do tomateiro em função de diferentes espaçamentos e doses de ácidos húmicos e flúvicos.

\begin{tabular}{|c|c|c|c|c|c|}
\hline \multicolumn{6}{|c|}{ Espaçamento (cm) (A) } \\
\hline & $\mathrm{APC}(\mathrm{cm})$ & $\mathrm{AP}(\mathrm{cm})$ & $\mathrm{DC}(\mathrm{mm})$ & $\mathrm{TCA}_{\mathrm{AP}}\left(\mathrm{cm} \mathrm{dia}^{-1}\right)$ & CLOR (ICF) \\
\hline 30 & $46,19 \mathrm{a}$ & $130,11 \mathrm{a}$ & $12,57 \mathrm{a}$ & $2,53 \mathrm{a}$ & $54,32 \mathrm{~b}$ \\
\hline 50 & $49,27 \mathrm{a}$ & $132,19 \mathrm{a}$ & $11,51 \mathrm{~b}$ & $2,58 \mathrm{a}$ & $56,41 \mathrm{a}$ \\
\hline \multicolumn{6}{|c|}{ Ácidos húmicos e fúlvicos $\left(\mathrm{L} \mathrm{ha}^{-1}\right)$ (B) } \\
\hline 0 & 49,45 & 133,32 & 13,01 & 2,51 & (1) \\
\hline 20 & 46,23 & 130,13 & 12,01 & 2,53 & -- \\
\hline 40 & 46,56 & 128,50 & 12,95 & 2,60 & -- \\
\hline 60 & 47,47 & 131,96 & 12,49 & 2,82 & -- \\
\hline 80 & 48,94 & 131,84 & 12,42 & 2,30 & -- \\
\hline $\mathrm{F}(\mathrm{A})$ & 0,0594 & 0,6385 & 0,0006 & 0,3450 & 0,0345 \\
\hline $\mathrm{F}(\mathrm{B})$ & 0,6382 & 0,6946 & 0,8835 & 0,7414 & 0,5052 \\
\hline $\mathrm{F}(\mathrm{A} * \mathrm{~B})$ & 0,1884 & 0,1582 & 0,6570 & 0,2395 & 0,0357 \\
\hline $\mathrm{CV}(\%)$ & 10,50 & 5,36 & 4,26 & 19,36 & 5,42 \\
\hline
\end{tabular}

*Médias seguidas por letras iguais, nas colunas não diferem entre si pelo teste de Tukey até 5\% de probabilidade. CV\%: Coeficiente de Variação. (1) Interação significativa entre o fator espaçamentos e o fator doses de ácidos húmicos e fulvicos.

As plantas de tomate espaçadas em $50 \mathrm{~cm}(20.000$ plantas $\mathrm{ha}^{-1}$ ) também apresentaram teores de clorofila significativamente superiores àquelas espaçadas em 30 cm (33.333 plantas ha $\left.{ }^{-1}\right)$. Segundo Streck et al. (1998), a competição interplanta assume importância, uma vez que o total de assimilados da planta em função da densidade de fluxo de radiação incidente, da concentração de $\mathrm{CO} 2$ e da área foliar é diretamente proporcional à fotossíntese, de modo que no aumento da população de plantas ocorre um sombreamento.

Para os teores de clorofila houve interação dos espaçamentos em função das doses de ácidos húmicos e fúlvicos, cuja resposta aumentou linearmente com o incremento das doses do fertilizante nas plantas espaçadas em $30 \mathrm{~cm}$, enquanto que, nas plantas conduzidas no espaçamento de $50 \mathrm{~cm}$ ocorreu uma diminuição linear nos teores de clorofila com o aumento das doses (Figura 1). Na menor densidade de cultivo, a planta possui mais espaço para expandir suas folhas, ocorrendo menor sobreamento mútuo; ocorre maior interceptação de luz por planta e, consequentemente, maior crescimento individual (ANDRIOLO et al., 2004). Desta forma, em plantas no sistema de cultivo mais adensados, as doses de ácidos húmicos e fúlvicos foram mais eficientes em relação ao sistema menos adensado, portanto esse efeito de competição foi suprido com o aumento das doses dos ácidos.

No que se refere às avaliações tecnológicas da qualidade dos frutos de tomate, observa-se na Tabela 2 que o potencial hidrogeniônico, acidez total titulável, firmeza de polpa, sólidos solúveis totais e índice de maturação do tomateiro híbrido Santy, não foram significativamente influenciados pela variação de espaçamento de plantio.

Na Tabela 2, observa-se que houve diferença significativa para as doses de ácidos húmicos e flúvicos para a variável firmeza, tais resultados divergem de
Yildirim (2007) e Pires et al. (2009), onde revelam que em frutos de tomates e outras espécies é comprovada a ação das substâncias húmicas na qualidade de frutos e ainda tem se destacado os seus efeitos sobre atributos como sólidos solúveis totais, acidez total titulável, $\mathrm{pH}$ e firmeza de frutos. Para Lima et al. (2011), os ácidos húmicos produzem um pequeno efeito significativo na qualidade dos frutos do tomateiro em relação aos teores de sólidos solúveis totais e acidez total titulável.

De acordo com Lima et al. (2011), frutos de tomates de alta qualidade são caracterizados por conter mais do que 0,32 de ATT, $3{ }^{\circ}$ Brix de SS e uma relação SS/ATT maior do que 10. Os teores de ATT e SS encontrados neste trabalho estão dentro dos limites estabelecidos pelos referidos autores. Entretanto a relação SS/ATT está abaixo do limite estabelecido.

Verificou-se que houve efeito da interação apenas para a firmeza de polpa entre os espaçamentos de plantio e as doses de ácido húmico e fúlvico (Tabela 2, Figura 2). Para firmeza de polpa de frutos os dados se ajustaram às regressões lineares, nas populações com espaçamentos de 30 e $50 \mathrm{~cm}$ dentro da linha de plantio do tomateiro (Figura 2).

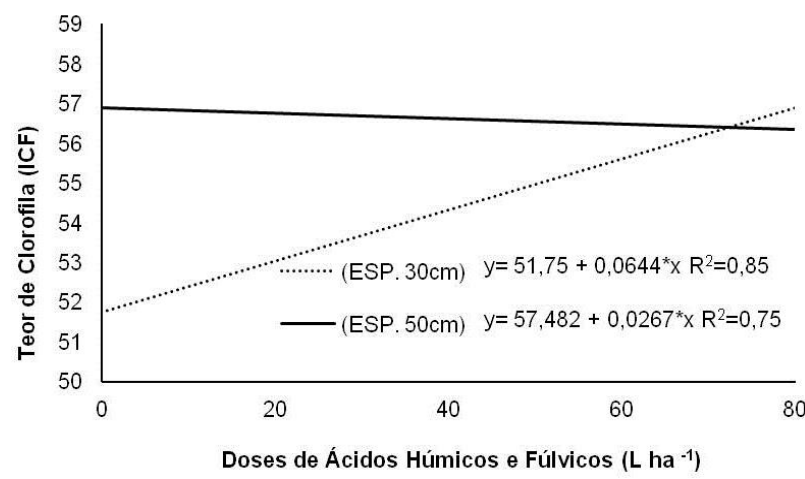

Figura 1. Teores de clorofila nas folhas do tomateiro (Solanum lycopersicum L.) em função das doses de ácidos húmicos e fúlvicos, cultivados em duas densidades de plantio. 
Tabela 2. Valores médios de potencial hidrogeniônico $(\mathrm{pH})$, acidez total titulável (ATT); firmeza de polpa (FZP), sólidos solúveis totais (SS) e índice de maturação (SS/ATT) em plantas de tomateiro cultivadas sob diferentes espaçamentos e doses de àcidos húmicos e flúvicos.

\begin{tabular}{|c|c|c|c|c|c|}
\hline \multicolumn{6}{|c|}{ Espaçamento (cm) (A) } \\
\hline & $\mathrm{pH}$ & ATT & FZP (lb pol-2 $)$ & SS $\left({ }^{\circ}\right.$ Brix $)$ & SS/ATT \\
\hline 30 & $4,25 \mathrm{a}$ & $0,44 \mathrm{a}$ & $10,53 \mathrm{a}$ & $4,26 \mathrm{a}$ & $9,68 \mathrm{a}$ \\
\hline 50 & $4,26 \mathrm{a}$ & $0,43 \mathrm{a}$ & $11,01 \mathrm{a}$ & $4,20 \mathrm{a}$ & $9,76 \mathrm{a}$ \\
\hline \multicolumn{6}{|c|}{ Ácidos húmicos e fúlvicos $\left(\mathrm{L} \mathrm{ha}^{-1}\right)(\mathrm{B})$} \\
\hline 0 & 4,25 & 0,45 & (1) & 4,18 & 9,27 \\
\hline 20 & 4,24 & 0,44 & -- & 4,18 & 8,96 \\
\hline 40 & 4,26 & 0,45 & -- & 4,30 & 9,42 \\
\hline 60 & 4,25 & 0,41 & -- & 4,08 & 9,88 \\
\hline 80 & 4,27 & 0,43 & -- & 4,38 & 8,73 \\
\hline $\mathrm{F}(\mathrm{A})$ & 0,5077 & 0,7997 & 0,0564 & 0,5253 & 0,5535 \\
\hline $\mathrm{F}(\mathrm{B})$ & 0,8650 & 0,5192 & 0,0001 & 0,1989 & 0,7909 \\
\hline $\mathrm{F}(\mathrm{A} * \mathrm{~B})$ & 0,7889 & 0,2524 & 0,0135 & 0,5507 & 0,3739 \\
\hline $\mathrm{CV}(\%)$ & 1,68 & 10,02 & 7,21 & 6,09 & 19,73 \\
\hline
\end{tabular}

*Médias seguidas por letras nas colunas não diferem entre si pelo teste de Tukey até 5\% de probabilidade; CV (\%): coeficiente de variação. (1) interação significativa entre o fator espaçamentos e o fator doses de ácidos húmicos e fulvicos.

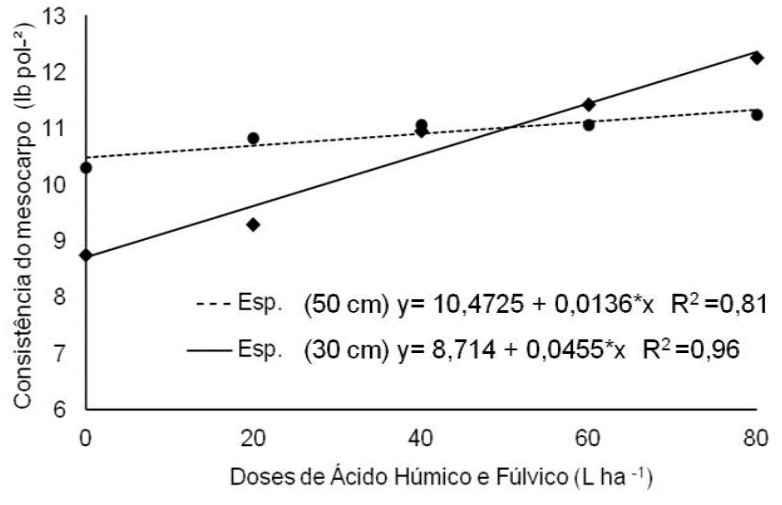

Figura 2. Consistência do mesocarpo dos frutos do tomateiro (Solanum lycopersicum L.) em função das doses de ácidos húmicos e fúlvicos, cultivados em duas densidades de plantio.

Resende et al. (2004) e Pires et al. (2009) constataram que o efeito das doses de substâncias húmicas sobre a firmeza de frutos de tomate depende do substrato utilizado e apresenta efeitos diferentes de acordo com a dose de ácidos húmicos e fúlvicos utilizada. A firmeza é um importante fator de qualidade em tomates para o consumo in natura, pois indica a tolerância do fruto ao transporte e ao manuseio, durante a colheita e a comercialização (PIRES et al., 2009).

Em relação à produção, observa-se na Tabela 3 diferenças significativas na distribuição percentual de frutos médios e grandes. A produção de frutos pequenos em ambos espaçamentos foi semelhante. Enquanto que, para os frutos médios das plantas cultivadas sob maior densidade de plantio, produziu percentual de frutos inferior àquelas com o espaçamento reduzido. Já para frutos grandes, o adensamento de plantas proporcionou a produção significativamente superior.

Houve efeito da interação apenas para o percentual de frutos médios, em função das doses de ácido húmico e fúlvico e dos espaçamentos de 30 e $50 \mathrm{~cm}$ entre plantas (Tabela 3, Figura 3). De acordo com Mueller e Wamser (2009), a variação de espaçamentos de plantio apresenta grande importância dentro da cadeia de técnicas de cultivo do tomateiro, podendo interferir no ciclo da planta, no controle de doenças, na qualidade e na quantidade de frutos colhidos.

Observou-se que a variação no percentual de frutos médios no espaçamento de $30 \mathrm{~cm}$ entre plantas, se ajustou a uma regressão linear positiva aumentando o percentual, enquanto que, para as plantas cultivadas no espaçamento de $50 \mathrm{~cm}$ entre plantas, o ajuste foi quadrático, com mínimo percentual de frutos médios para a dose estimada de 62,64 $\mathrm{L} \mathrm{ha}^{-1}$ (Figura 3).

Tabela 3. Valores médios para frutos pequenos (FP), frutos médios (FM), frutos grandes (FG) e a produtividade do tomateiro em função de diferentes espaçamentos e doses de ácidos húmicos e flúvicos.

\begin{tabular}{|c|c|c|c|c|}
\hline \multicolumn{5}{|c|}{ Espaçamento (cm) (A) } \\
\hline & $\mathrm{FP}(\%)$ & $\mathrm{FM}(\%)$ & $\mathrm{FG}(\%)$ & $\begin{array}{c}\text { Produtividade } \\
\quad\left(\mathrm{kg} \mathrm{m}^{2}\right)\end{array}$ \\
\hline 30 & $21,68 \mathrm{a}$ & $37,96 \mathrm{a}$ & $40,35 \mathrm{~b}$ & $5,64 \mathrm{~b}$ \\
\hline 50 & $20,81 \mathrm{a}$ & $34,93 \mathrm{~b}$ & $44,24 \mathrm{a}$ & $6,69 \mathrm{a}$ \\
\hline \multicolumn{5}{|c|}{ Ácidos húmicos e fúlvicos $\left(\mathrm{L} \mathrm{ha}^{-1}\right)(\mathrm{B})$} \\
\hline 0 & 21,86 & (1) & 45,50 & 6,39 \\
\hline 20 & 22,68 & -- & 41,27 & 5,78 \\
\hline 40 & 20,20 & -- & 44,23 & 6,08 \\
\hline 60 & 20,84 & -- & 44,54 & 6,21 \\
\hline 80 & 20,95 & -- & 35,71 & 6,30 \\
\hline$\overline{\mathrm{F}(\mathrm{A})}$ & 0,0201 & 0,6210 & 0,0135 & 0,0054 \\
\hline $\mathrm{F}(\mathrm{B})$ & 0,5982 & 0,0166 & 0,6806 & 0,4041 \\
\hline $\mathrm{F}(\mathrm{A} * \mathrm{~B})$ & 0,1264 & 0,0021 & 0,7377 & 0,1917 \\
\hline$\overline{\mathrm{CV}}(\%)$ & 18,82 & 16,69 & 28,36 & 10,76 \\
\hline
\end{tabular}

*Médias seguidas por letras iguais nas colunas não diferem entre si pelo teste de Tukey até $5 \%$ de probabilidade; $\mathrm{CV}(\%)$ : coeficiente de variação. (1) interação significativa entre o fator espaçamentos e o fator doses de ácidos húmicos e fulvicos. 


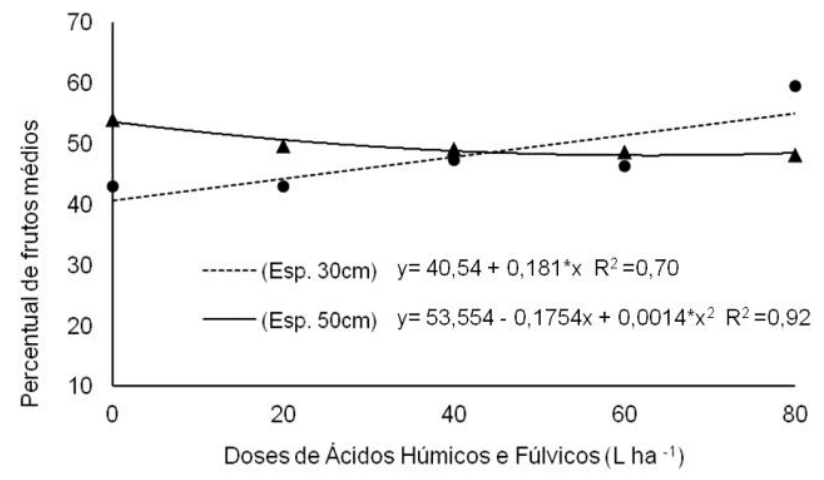

Figura 3. Número de frutos de tamanho médio do tomateiro (Solanum lycopersicum L.) em função das doses de ácidos húmicos e fúlvicos, cultivados em duas densidades de plantio.

A produtividade do tomateiro foi significativamente modificada pelos diferentes espaçamentos. $\mathrm{O}$ maior rendimento produtivo foi obtido quando as plantas de tomate foram conduzidas no espaçamento de $50 \mathrm{~cm}$ entre plantas (Tabela 3).

A produtividade se apresenta $16 \%$ superior àquela obtida nas plantas cultivadas com $30 \mathrm{~cm}$ entre plantas. De maneira geral, a produtividade alcançada neste experimento está próxima à obtida por Seleguini et al. (2016), quando alcançaram produção média de $6,28 \mathrm{~kg}$ $\mathrm{m}^{-2}$ de tomate do híbrido AF 7631 utilizando diferentes concentrações de paclobutrazol e inferior aos resultados de Silva e Faria Junior (2011), cuja produtividade média, para o mesmo híbrido, girou em torno de $10 \mathrm{~kg}$ $\mathrm{m}^{-2}$.

As aplicações das doses de ácidos húmicos e fúlvicos não promoveram mudanças significativas na produtividade (Tabela 3). Esses resultados corroboram com os de Lima et al. (2011) que não observaram efeitos significativos dos ácidos húmicos aplicados a diferentes substratos em relação à produção total de fruto comercial e não comercial.

\section{Conclusões}

Para o adequado cultivo de tomate do Híbrido Santy recomenda-se a densidade de plantio de 20.000 plantas ha $^{-1}$ e doses decrescentes de substâncias húmicas, garantindo assim alta produtividade de frutos de alta qualidade.

\section{Agradecimentos}

À Coordenadoria Central de bolsas da Universidade Estadual de Goiás pelo apoio financeiro.

\section{Referências Bibliográficas}

ANDRIOLO, J. L.; ESPÍNOLA, M. C. G.; GODÓI, R.; BORTOLOTTO, O. C.; LUZ, G. L. Crescimento e produtividade de plantas de tomateiro em cultivo protegido sob alta densidade e desfolhamento. Ciência Rural, Santa Maria-RS, v. 34, n. 4, p.1251-1253, 2004.

BALDOTTO, M. A.; BALDOTTO, L. E. B. Gladiolus development in response to bulb treatment with different concentrations of humic acids. Revista Ceres, Viçosa-MG, v. 60, n. 1, p. 138-142, 2013.

BALDOTTO, M. A.; BALDOTTO, L. E. B. Ácidos húmicos. Revista Ceres, Viçosa-MG, v. 61, supl, p. 856$881,2014$.

BALDOTTO, L. E. B.; BALDOTTO, M. A.; GONTIJO, J. B.; OLIVEIRA, F. M.; GONÇALVES, J. Aclimatização de orquídea (Cymbidium sp.) em resposta à aplicação de ácidos húmicos. Ciência Rural, Santa Maria-RS, v. 44, n. 5, p. 830833,2014

BERNARDES, J. M.; REIS, J. M. R.; RODRIGUES, J. F. Efeito da aplicação de substância húmica em mudas de tomateiro. Global Science and Technology, Rio Verde-GO, v. 4, n. 3, p. 92-99, 2011.

EMBRAPA. EMPRESA BRASILEIRA DE PESQUISA AGROPECUÁRIA. Sistema brasileiro de classificação de solos. 3. ed. Rio de Janeiro-RJ: Ministério da Agricultura, Pecuária e Abastecimento. 2013. 353 p.

FILGUEIRA, F. A. R. Novo Manual de olericultura: agrotecnologia moderna na produção e comercialização de hortaliças. 3. ed. Viçosa-MG: UFV, 2012. 421 p.

HUNT R. Basic growth analysis. London: Unwin Hyman, 1990. $112 \mathrm{p}$.

KÖPPEN, W.; GEIGER, R. Klimate der Erde. Gotha: verlag justus perthes. Wall-map. 1928.

LIMA, A. A.; AVARENGA, M. A. R.; RODRIGUES, L.; CARVALHO, J. G. Concentração foliar de nutrientes e produtividade do tomateiro cultivado sob diferentes substratos e doses de ácidos húmicos. Horticultura Brasileira, BrasíliaDF, v. 29, n. 1, p. 63-69, 2011.

MACHADO, A. Q.; ALVARENGA, M. A. R.; FLORESTINO, C. E. T. Produção de tomate italiano (Saladete) sob diferentes densidades de plantio e sistemas de poda visando ao consumo in natura. Horticultura Brasileira, Brasília-DF, v. 25. n. 2, p. 149-153, 2007.

MEURER, E. J. Fundamentos de Química do Solo. Porto Alegre-RS. 2012. p. 63-66.

MUELLER, S.; WAMSER A. F. Combinação da altura de desponte e do espaçamento entre plantas de tomate. Horticultura Brasileira, Brasília-DF, v. 27, n. 1, p. 64-69, 2009.

PIRES, C. R. F.; LIMA, L. C. O.; BOAS, E. V. B.; ALVES, R. R. Qualidade textural de tomates cultivados em substratos orgânicos submetidos à aplicação de substâncias húmicas. Pesquisa Agropecuária Brasileira. Brasília-DF, v. 44, n. 11, p. 1467-1472, 2009.

PBMH. PROGRAMA BRASILEIRO PARA A MODERNIZAÇÃO DA HORTICULTURA - Normas de 
classificação do tomate. São Paulo: Centro de Qualidade em Horticultura - CQH/CEAGESP, 2003. (Documentos, 26).

RESENDE, J. M.; CHITARRA, M. I.; MALUF, W. R.; CHITARRA, A. B.; SAGGIN JUNIOR, O. J. Atividade de enzimas pectinametilesterase e poligalacturonase durante o amadurecimento de tomates do grupo multilocular. Horticultura Brasileira, Brasília-DF, v. 22, n. 2, p. 206-201, 2004.

SELEGUINI, A.; VENDRUSCOLO, E. P.; CAMPOS, L. F. C.; FARIA JUNIOR, M. J. A. Efeito do paclobutrazol sobre o crescimento de plantas e produção de tomate (Solanum lycopersicum L.) em ambiente protegido. Scientia Agropecuaria, Trujillo, v. 7, n. 4, p. 391-399, 2016.

SILVA, K. S.; FARIA JUNIOR, M. J. A. Uso de paclobutrazol como estratégia para redução do porte e da brotação lateral de plantas de tomateiro. Ciência e Agrotecnologia, Lavras-MG, v. 35, n. 3, p. 539-546, 2011.
STRECK, N.A.; BURIOL, G.A.; ANDRIOLO, J.L.; SANDRI, M.A. Influência da densidade de plantas e da poda apical drástica na produtividade do tomateiro em estufa de plástico. Pesquisa Agropecuária Brasileira, Brasília-DF, v. 33, n. 7, p. 1105-1112, 1998.

WANGEN, D. R. B.; MENDES, L. F.; SAGATA, E.; SILVA, H. C.; SHIMAMOTO, G. F. Fertilizante orgânico na produção de couve-da-malásia, Brassica chinensis var. parachinensis (Bailey) Sinskaja. Enciclopédia Biosfera, Goiânia-GO, v. 9 , n. 17, p. 1429-1435, 2013.

YILDIRIM, E. Foliar and soil fertilization of humic acid affect productivity and quality of tomato. Acta Agricultura e Scandinavica, Stockholm, v. 57, n. 2, p. 182-186, 2007.

ZANDONADI, D. B; SANTOS, M. P; MEDICI, L. O; SILVA, J. Ação da matéria orgânica e suas frações sobre a fisiologia de hortaliças. Horticultura Brasileira, Brasília-DF, v. 32 , n. 1. p. $14-20,2014$ 